\title{
Role of Raf-kinase inhibitor protein in colorectal cancer and its regulation by hydroxycamptothecine
}

\author{
Fang Nie', Jianguo Cao ${ }^{1}$, Jinlu Tong ${ }^{2}$, Mingming Zhu², Yuan Gao ${ }^{1}$ and Zhihua Ran ${ }^{2 *}$
}

\begin{abstract}
Background: Recently accumulated evidence suggests that Raf kinase inhibitor protein (RKIP) participates in regulation of many signaling pathways and plays an important role in tumorigenesis and tumor metastasis. However, studies investigating the role of RKIP in colorectal cancer have not been reported. The aim of this study was to investigate the role of RKIP on colorectal cancer cell differentiation, progression and its correlation with chemosensitivity.

Results: Immunohistochemical analysis revealed that RKIP expression was higher in non-neoplastic colorectal tissue (NCRCT) and colorectal cancer tissue (CRCT) than that in metastatic lymph node tissue (MLNT) $(P<0.05)$. P-ERK protein expression was higher in MLNT and CRCT than that in NCRCT $(P=0.02)$. Immunocytochemical analysis further revealed that RKIP expression was higher in the well differentiated cell line SW1116 as compared to that in the poorly differentiated cell line LoVo. Matrigel invasive assay demonstrated that the inhibition of RKIP by short hairpin RNA (shRNA) 271 transfection significantly increased the number of migrated cells $(90.67 \pm 4.04$ vs. $37.33 \pm 2.51, P<0.05)$, whereas over-expression of RKIP by PEBP-1 plasmid transfection significantly suppressed the number of migrated cells (79.24 \pm 5.18 vs. $154.33 \pm 7.25, P<0.05$ ). Meanwhile, down-regulation of RKIP induced an increase in the cell survival rate by inhibiting apoptosis induced by hydroxycamptothecine.

Conclusions: RKIP was also found to be associated with cell differentiation, with a higher activity in well differentiated colorectal cancer cells than in poorly differentiated ones. The upregulated expression of RKIP in colorectal cancer cells inhibited cell invasion and metastasis, while downregulation of RKIP reduced chemosensitivity by inhibiting apoptosis induced by HCPT.
\end{abstract}

Keywords: Colorectal cancer, Hydroxycamptothecine, Role, Raf-kinase inhibitor protein

\section{Background}

The Raf kinase inhibitor protein (RKIP), a member of an evolutionarily conserved family of phosphatidylethanolamine-binding proteins (PEBPs), has been recognized as a representative of a new class of modulators of signaling cascades that serve to maintain the balance of biological systems. RKIP inhibits kinase signaling pathways and metastasis. A vast array of studies have been conducted to understand the role of RKIP in various malignancies such as melanoma [1], prostate cancer [2],

\footnotetext{
*Correspondence: zhihuaran@vip.163.com

${ }^{2}$ Division of Gastroenterology and Hepatology, Ren Ji Hospital, School of Medicine, Shanghai Jiao Tong University, Shanghai Institute of Digestive Disease, 145 Middle Shandong Road, Shanghai 200001, China

Full list of author information is available at the end of the article
}

breast cancer [3], gastric cancer [4], glioblastoma [5], lung cancer [6], and myelogenous leukemia [7]. Most notably, RKIP has been identified as a modulator of extracellular signal-regulated kinase (ERK) [8], nuclear factor-kappa B (NFkB) [9], and G protein coupled receptor (GPCR) [10, 11] signaling cascades. Moreover, RKIP has been implicated in tumor biology. Down-regulation of RKIP significantly correlated with radio-resistance-induced relapse [12]. RKIP sensitizes prostate and breast cancer cells to drug-induced apoptosis [13]. RKIP as a suppressor of metastasis has been confirmed as a predictor of cancer progression and is even being considered as a potential therapeutic target.

Recently, RKIP was found to inhibit proliferation of activated hepatic stellate cells by down-regulation of

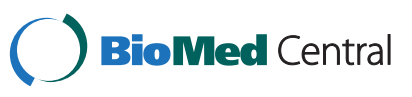


mitogen-activated protein kinase (MAPK) signaling, but was found to promote the migration of hepatic stellate cells and wound closure [14]. Surprisingly, in the merkel cell carcinoma cell line UISO, RKIP knockdown does not alter proliferation or chemosensitivity to cisplatin, and has no effect on blocking the MAP kinase pathway [15]. RKIP does not appear to play exactly the same role in different cancers and non-malignant cells. This may be because of the diverse molecular functioning milieu, different cell proliferation signaling pathways active in different tissues and other mechanisms that are as yet unknown.

In developed countries, colorectal cancer (CRC) is the third-most frequent cancer and the second-most common cause of cancer-related death [16]. Chemotherapeutic drug resistance remains a major obstacle to the successful treatment of colorectal cancer. RKIP silencing has been correlated significantly with KEAP1 degradation and bestowed resistance to cisplatin by up-regulating NRF2 gene in HER-293 cells. Also, expression levels of RKIP/KEAP1 have relationship with the extent of apoptosis after treatment with adriamycin in HT29 cells [17]. In normal colonic mucosa, cytoplasmic RKIP expression was found in $100 \%$ of cells [18]. A study suggested that RKIP is probably a downstream effector in TWEAK (Tumor necrosis factor-like weak inducer of apoptosis) mediated invasion inhibition. Knockdown of RKIP expression in HCT116 cells by short hairpin RNA (shRNA) resulted in increased invasiveness [19]. Loss of RKIP was also found to be associated with $\mathrm{N}$ stage disease, the presence of vascular invasion, metastasis and worse survival time in mismatch repair-proficient CRC [18]. RKIP expression in primary CRCs can be useful for identifying early-stage CRC patients at risk of relapse [20]. It is plausible that RKIP plays an important role in the occurrence and development of colorectal cancer. However, few studies exploring the role of RKIP in colorectal cancer have been reported and the specific mechanism still remains unresolved.

In our paper, we shall first investigate the effect of RKIP on differentiation, invasion and metastasis of colorectal cancer cells, both in vivo and in vitro. Later, the association between RKIP and chemosensitivity to hydroxycamptothecine (HCPT) would be assessed, including the underlying mechanism.

\section{Methods}

\section{Cell culture}

Two human colorectal cancer cell lines SW1116 and SW480 were cultured in RPMI 1640 medium (Gibco, Carlsbad, CA) with $10 \%$ fetal bovine serum. LoVo cells (human colon adenocarcinoma cell line) were cultured in F-12 k medium with $10 \%$ fetal bovine serum. Two other human colorectal cancer lines, HT-29 and HCT-116 were cultured in McCoy's 5A medium
(Sigma, Louis, MO) with $10 \%$ fetal bovine serum. Caco-2 (human colon adenocarcinoma cell line) cells were cultured in DMEM medium (Gibco, Carlsbad, CA) with $10 \%$ fetal bovine serum. All cells were incubated at $37{ }^{\circ} \mathrm{C}$ in humidified $5 \% \mathrm{CO}_{2}$. HCPT-resistant cell line of human colon cancer cell, SW1116/HCPT, was developed by stepwise increasing concentration method [21].

\section{Patients and tissue samples}

Thirty non-neoplastic colorectal tissue (NCRCT) samples and 30 colorectal cancer tissue (CRCT) samples were surgically obtained from patients admitted from 2007 to 2009 in the Department of General Surgery at Shanghai Renji Hospital, China. Another 30 matching metastatic lymph node tissue (MLNT) samples archived in formalin-fixed paraffin-embedded tissue blocks were obtained from Department of Pathology, Shanghai Renji Hospital, China.

\section{Immunohistochemistry and immunocytochemistry}

For immunohistochemistry (IHC), sections of paraffinembedded tissues were deparaffinized in xylene, rehydrated in graded alcohol solutions, and treated with an antigen retrieval solution $(10 \mathrm{mmol} / \mathrm{L}$ sodium citrate buffer, $\mathrm{pH}$ 6.0). For IHC, cells were incubated at the density of $2 \times 10^{4}$ cells $/ \mathrm{cm}^{2}$ in 6 -well culture plate with glass slice. A three-step streptavidin-biotin horseradish peroxidase method was used, and the expression of RKIP and pERK was examined with the primary antibodies (RKIP, Santa Cruz, dilution 1:200; pERK, Santa Cruz, dilution 1:50) using the SP kit (ZYMED, San Diego, America), according to the manufacturer's instructions. Protein expression was quantified based on a 3-point positive scale (+: 0 to $2 ;++: 3$ to $4 ;+++: 5$ to 9 ). The scale ranking equaled the product of staining intensity score (4-point scale: negative-0; weak-1; intermediate-2; and strong-3) and staining extent score (percentage of positive tumor cells: $0-0 \%$ to $10 \% ; 1-15 \%$ to $50 \% ; 2-51 \%$ to $75 \%$ and $3->75 \%)$. The percentage of positive cells was calculated by counting more than 100 cancer cells in randomly selected high-power fields (400x). All samples were analyzed by two senior pathologists.

\section{Real-time polymerase chain reaction}

One $\mu \mathrm{g}$ of RNA was reverse transcribed using RT kit (Takara, Tokyo, Japan). Quantitative real-time polymerase chain reaction (PCR) was performed with a SYBR Green real-time premix kit (Takara, Tokyo, Japan). Forward (F) and reverse (R) primer sequences were as follows: RKIP(F)5' -agcagtggcacagtcctc-3',(R) 5' -tggtctccagatcggttg3'; GAPDH(F) 5' -gcaccgtcaaggctgagaac-3', (R) 5' -atggtggtg aagacgccagt- $3^{\prime}$. PCR was performed for $30 \mathrm{~s}$ at $95^{\circ} \mathrm{C}, 5 \mathrm{~s}$ at $95^{\circ} \mathrm{C}$ and $31 \mathrm{~s}$ at $60^{\circ} \mathrm{C}$ for 40 cycles. 


\section{Stable transfection and G418 screening of stable expression cell lines}

PGPU6/GFP/Neo-PEBP1-501/271/376 (RKIP shRNA vector, RKIP GenBank Number: NM-002576) and PGPU6/ GFP/Neo-sh NC (negative control) were obtained from Gene Pharma, Inc. (Shanghai, Co). SW1116 cells were transfected with each shRNA using Lipofectamine 2000 reagent (Invitrogen, Carlsbad, CA) as per the manufacturer's protocol. The silencing effect of RKIP was confirmed by real-time PCR and Western blot analysis. SW1116 cells were transfected with the shRNA that had the best silencing effect, and screened by G418 (Sigma). The best screening concentration of G418 for SW1116 cells was $800 \mu \mathrm{g} / \mathrm{mL}$. After one month of selection in RIPM-1640 medium containing 800 mg/mL G418. Individual neomycin-resistant colonies were isolated and expanded.

\section{Western blotting}

Western blot analysis was performed using the standard methodology as described previously [22]. The cells were lysed in RIPA Lysis Buffer (Beyotime, Shang-hai, CH); equal amount of protein $(100 \mu \mathrm{g} /$ lane $)$ from whole-cell lysates were subjected to SDS-PAGE. Proteins were transferred to microporous PVDF membranes (Millipore, Massachusetts, CA) and were probed with specific primary antibodies, followed by the appropriate HRPconjugated secondary antibodies (Pierce, Rockford, USA). The antibodies used in this study were rabbit monoclonal antibody RKIP (Santa Cruz, Inc, 1:200 dilution), rabbit polyclonal antibody P-ERK (Santa Cruz, Inc, 1:100 dilution), GAPDH (Kang-chen, Shang-hai, $\mathrm{CH}$. 1:1000). Proteins were detected using the enhanced chemiluminescence detection kit (Super Signal West Femto Substrate, Pierce).

\section{Apoptosis assay}

Apoptosis was demonstrated using Annexin V-FITC apoptosis detection kit (Abcam, USA) according to manufacturer's protocol. About $1 \times 10^{6}$ cells were collected and immediately analysed using a flow cytometer (BD, San Diego, CA).

\section{Matrigel invasion assay}

Matrigel invasion assay was performed using transwell insert chamber $(8.0 \mu \mathrm{m}$ pore polycarbonate membranes, Corning, Inc.) coated with Matrigel (BD, USA) as per the manufacturer's protocol. Then $1 \times 10^{5}$ transfected cells were harvested and seeded in $0.1 \%$ FBS medium into the upper chamber, whereas medium supplemented with $20 \%$ FBS was applied to the lower chamber as a chemo attractant for inducing invasion. After $48 \mathrm{~h}$ of incubation, the migrant cells which were attached to the lower surface were fixed in $4 \%$ paraformaldehyde and stained with crystal violet. The number of migrated cells on the lower surface of the membrane was counted under an invert microscope by examining 10 fields.

\section{MTT assay and flow cytometry}

Cell viability was measured using MTT (3-(4,5-dimethylthiazol-2-yl)-2-5 diphenyl tetrazolium bromide) assay. $5 \times 10^{3}$ cells were incubated in a 96-well culture plate for $24 \mathrm{~h}$ followed by their treatment with different concentrations of HCPT for $48 \mathrm{~h}$. The supernatant was removed and $180 \mu \mathrm{L}$ cell culture fluid was added. $10 \mu \mathrm{L}$ of MTT (Sigma, M5665) dissolved in $100 \mu \mathrm{L}$ of phosphatebuffered saline (Sigma P4417) was added followed by incubation for $4 \mathrm{~h}$ at $37{ }^{\circ} \mathrm{C}$ in a humid, $5 \% \mathrm{CO}_{2}$ atmosphere. After this, the supernatant was removed, and the insoluble formazan crystals were dissolved in $150 \mu \mathrm{L}$ of dimethyl sulfoxide. The absorbance was read in a microplate reader model 550 ELISA plate reader (BioRAD, Hercules, USA) at $570 \mathrm{~nm}$.

\section{Statistical analysis}

All statistical analyses were performed with SPSS version 13.0 software (SPSS, Chicago, IL, USA). The results of IHC were analyzed using Pearson's chi-square-test and descriptive statistics. In-vitro results were expressed as mean \pm standard deviation, and the data were analyzed for significance by ANOVA. A value of $P<0.05$ was considered to be statistically significant.

\section{Results}

Detection of RKIP and P-ERK expression in CRCT, NCRCT and MLNT by immunostaining

The expression of RKIP was found throughout in the cytoplasm of NCRCT and CRCT, with no significant difference between the two. However, the expression negligible in MLNT. The protein expression of P-ERK was positive in CRCT and MLNT, while it was negative in NCRCT. P-ERK staining was also mainly in the cytoplasm, with occasional nuclear staining (Fig. 1). The staining for RKIP was strong in NCRCT with " $3+$ " and in CRCT with "2+", while only very weak staining was detected in MLNT. The staining for P-ERK was very weak in NCRCT with no "3+", while strong staining was there in NCRCT and CRCT. To summarize, RKIP expression levels were higher in CRCT and NCRCT than in MLNT $\left(\chi^{2}=36.446,{ }^{* *} P<0.001\right)$. P-ERK expression levels were higher in MLNT and NCRCT than in CRCT $\left(\chi^{2}=11.675, " P<0.05\right)$ (Table 1 and Fig. 2 ).

\section{Role of RKIP expression in colonic cancer differentiation}

We selected colon cell lines ranging from low-to-high grade of differentiation. RKIP was detected in some part of cytoplasm in all cell lines. The results showed that the expression of RKIP were higher in well differentiated cell 


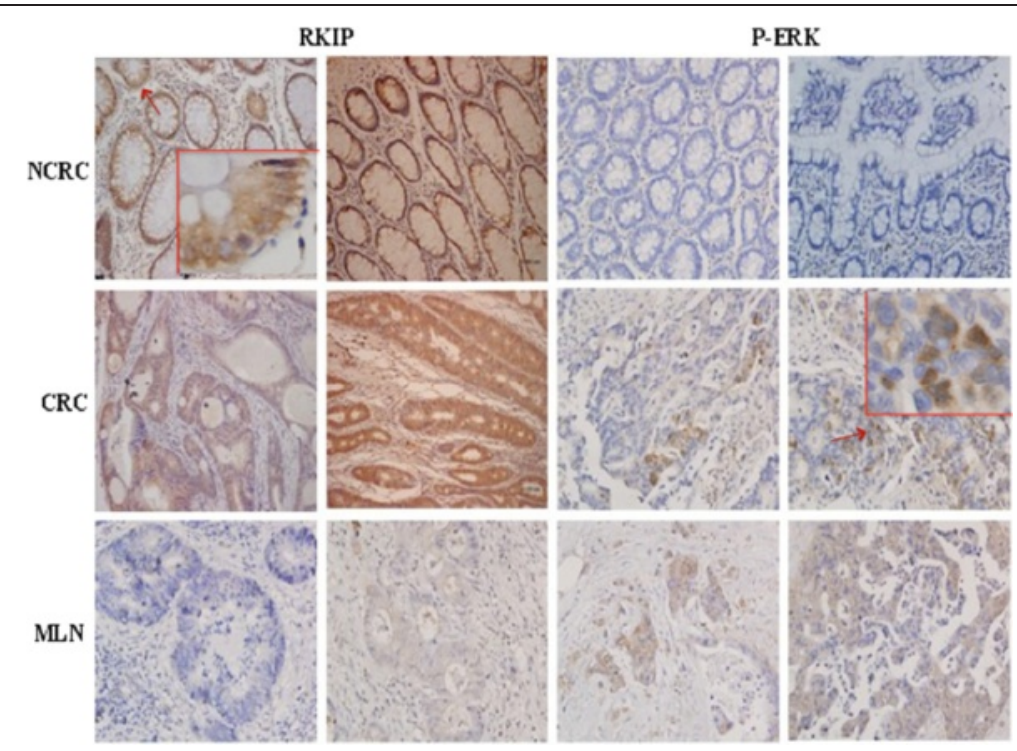

Fig. $1 \mathrm{Imm}$ monohistochemical staining of NCRCT, CRCT and MLNT with anti-RKIP and anti-P-ERK antibody. Strong RKIP expression was stained in NCRCT, CRCT; and weak in MLNT In contrast, P-ERK was weak to moderate in CRCT, MLNT, and no staining was observed in NCRCT. Magnification X100; Red arrows indicate the enlarged areas in red frames. Abbreviations: RKIP, Raf kinase inhibitor protein; NCRCT, non neoplastic colorectal tissue; $C R C T$, colorectal cancer tissue; MLNT, metastatic lymph node tissue

lines (HT-29, SW1116) than in poorly differentiated cell lines (LoVo) (Fig. 3a). At the same time, RKIP mRNA expressions in these colon cancer cell lines were also illustrated by real-time PCR. RKIP expression was highest in SW1116 cell line and the lowest in LoVo cell line (Fig. 3b: "P<0.05; $\left.{ }^{* * *} P<0.01\right)$. These results show the consistency in the results attained by two different approaches. The expression of RKIP was correlated to the degree of tumor cell differentiation. The staining intensity of RKIP protein decreased with the reducing differentiation.

The sub clone cells stably expressing RKIP antisense RNA were selected by G418 and named as SW1116/RKIPThe eukaryotic expression vector PIRES $_{2}$-EGFP/PEBP-1 can up-regulate RKIP expression in LoVo cells SW1116 with the highest RKIP protein in several cell lines were transfected with RKIP shRNA by lipofectamine and observed by fluorescence microscopy. The results showed a high transfection efficiency, while the

Table 1 The staining intensity of RKIP and P-ERK

\begin{tabular}{|c|c|c|c|c|c|c|}
\hline \multirow{2}{*}{$\begin{array}{l}\text { Colorectal } \\
\text { tissue(N) }\end{array}$} & \multicolumn{3}{|c|}{${ }^{* *} \mathrm{RKIP}$} & \multicolumn{3}{|c|}{${ }^{*}$ P-ERK } \\
\hline & + & ++ & +++ & + & ++ & +++ \\
\hline NCRCT(30) & 8 & 10 & 12 & 27 & 3 & 0 \\
\hline CRCT(30) & 8 & 17 & 5 & 17 & 10 & 3 \\
\hline MLNT(30) & 26 & 4 & 0 & 16 & 10 & 4 \\
\hline
\end{tabular}

NCRCT, non neoplastic colorectal tissue; CRCT, colorectal cancer tissue; MLNT, metastatic lymph node tissue; Statistical analysis: One-way analysis of variance was followed by the student-newman-keuls post-hoc test. ( ${ }^{*} P<0.001$, $\left.{ }^{*} P<0.05\right)$ plasmid shRNA271 had an obvious interfering effect (Fig. 4c). Positive clones were screened by G418 (Fig. 4a) and identified by the green fluorescent protein (GFP) expression (Fig. 4b), and named SW1116/RKIP- cells. The best screening concentration of G418 for SW1116 cells was $800 \mathrm{ug} / \mathrm{mL}$. The results showed the single cell clone all expression GFP (Fig. 4b). The RKIP protein expression was lower in SW1116/RKIP ${ }^{-}$than in SW1116 cells (Fig. 4d). In the poorly differentiated LoVo cells, that were transfected with the eukaryotic expression vector pIRES2-EGFP/PEBP-1 plasmid, an up-regulation of RKIP expression was observed (Fig. 4e).

\section{Down-regulation of RKIP promotes invasion in SW1116 cells while its up-regulation inhibits invasion and migration in LoVo cells}

To investigate the role of RKIP in human colorectal cancer invasion and metastasis, matrigel invasion assay was used to detect the difference of invasion and metastatic ability in SW1116 cells, SW1116/ RKIP ${ }^{-}$cells, LoVo cells and LoVo cells transfected with pIRES $_{2}$-EGFP/PEBP-1.

Under the same culture conditions and inoculation density, the down-regulation of RKIP in SW1116/RKIP ${ }^{-}$ increased the number of migrated cells on the lower surface of the matrigel-coated transwell membrane (90.67 \pm $4.04 v s .37 .33 \pm 2.51, P<0.01)$ at $72 \mathrm{~h}$. The up-regulation of RKIP in LoVo cells transfected with pIRES $_{2}$-EGFP/PEBP-1 reduced the number of migrated cells $(79.24 \pm 5.18 \mathrm{vs}$. $154.33 \pm 7.25, P<0.05)$ at $72 \mathrm{~h}$ (Fig. 5). There were no cell across the membrane at $24 \mathrm{~h}$, and only few cells were found across it in both the groups at $48 \mathrm{~h}$. 

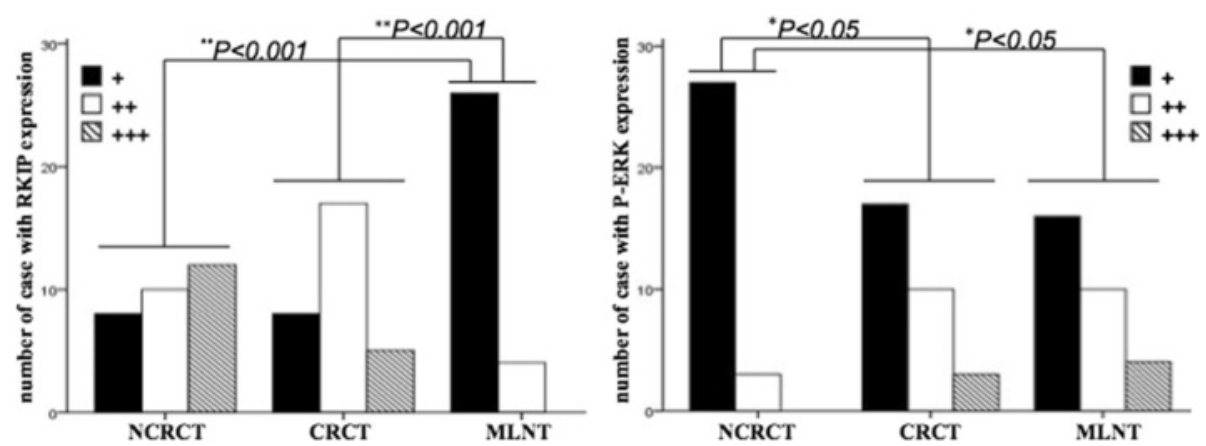

Fig. 2 The variable expression of RKIP protein and P-ERK protein in different tissues by clustered charts. X-axis represented a different tissue. NCRCT: $(N=30)$; $C R C T$ : $(N=30)$; MLNT: $(N=30)$; The positive staining of RKIP and P-ERK in different tissues are shown in Table 1. For RKIP: CRCT, NCRCT vs. MLNT $\left(x^{2}=36.446>x 20.05(4)\right.$, $\left.{ }^{* *} P<0.001\right)$. For P-ERK: MLNT, NCRCT vs. CRCT $\left(x^{2}=11.675>x^{2}=20.05(4)\right.$, $\left.{ }^{*} P<0.05\right)$; Abbreviations: RKIP, Raf kinase inhibitor protein; NCRCT, non neoplastic colorectal tissue; CRCT, colorectal cancer tissue; MLNT, metastatic lymph node tissue
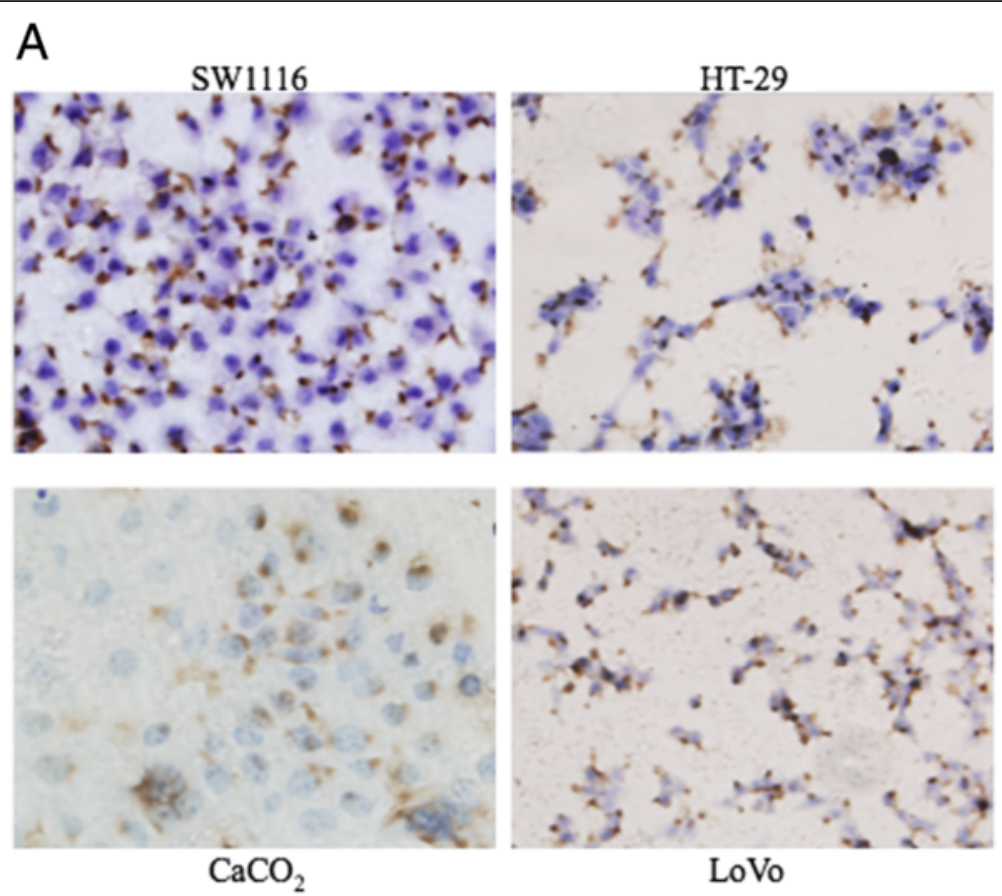

B

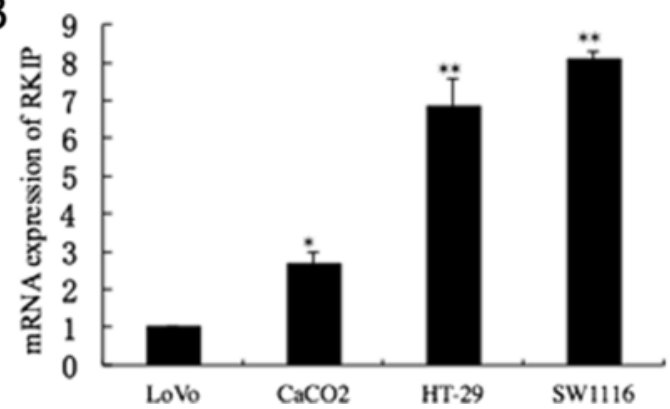

Fig. 3 RKIP expression in colorectal cancer cell lines; a Immunohistochemical staining of colorectal cancer cell lines (LoVo, CaCO2, HT-29, SW1116) with an RKIP antibody. RKIP expression was present in an area of the cytoplasm. RKIP was strongly stained in SW1116 cells. Hematoxylin was used for nuclear staining (Magnification $\times 400$ ); $\mathbf{b}$ mRNA expression of RKIP in cultured colorectal cancer cell lines. RKIP mRNA was detected by RT-PCR analysis, in 4 colorectal cancer cell lines (LoVo, CaCO2, HT-29, SW1116). Abbreviations: RKIP, Raf kinase inhibitor protein; RT-PCR, reverse transcriptase- polymerase chain reaction 

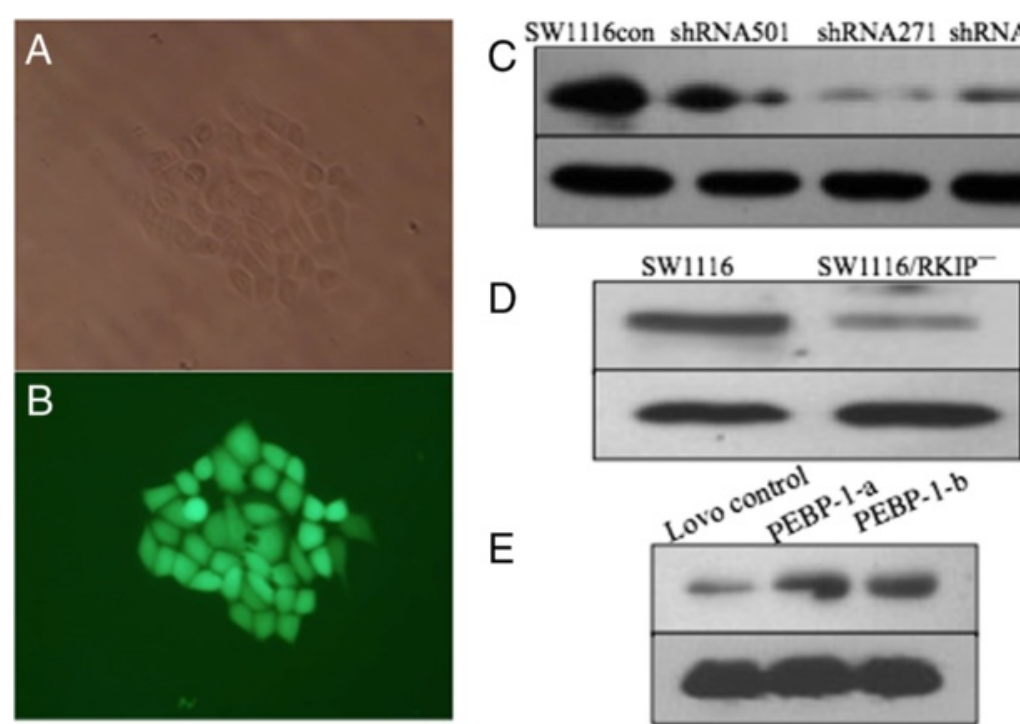

\section{RKIP \\ GAPDH}

RKIP

GAPDH

RKIP

GAPDH

Fig. 4 Establishment of the single clone SW1116/RKIP- cells and effect of shRNA vector (PGPU6/GFP/Neo-PEBP1-501/271/376 targeted RKIP), over-expression vector (plRES2-EGFP/PEBP-1). a SW1116 cells stably transfected with shRNA 271 were screened with G418 in $800 \mathrm{ug} / \mathrm{mL}$ to obtain single colony selection in 24 well culture plates under optical microscope; b A under fluorescence microscope; c SW1116 cells were stably transfected with either empty shRNA vector PGPU6/ GFP/Neo (SW1116 con) or shRNA vector PGPU6/GFP/Neo-PEBP1 -501/271/376 target RKIP (shRNA 501, 271,376) respectively. RKIP expression was analyzed by Western Blot. shRNA 271 caused significant down-regulation of RKIP expression. $\mathbf{d}$ In SW1116/RKIP- ${ }^{-}$cells, Western Blot verified the decrease in RKIP expression. e LoVo control: LoVo cells transfected with empty pIRES2-EGFP; PEBP-1-a: LoVo cells transfected with over-expression vector pIRES2-EGFP/PEBP-1, PEBP-1-b is repeated sample to PEBP-1-a. a, b, Magnification $\times 400)$. Abbreviations: RKIP, Raf kinase inhibitor protein; NCRCT, non neoplastic colorectal tissue; CRCT, colorectal cancer tissue; MLNT, metastatic lymph node tissue; PEBP, Phosphatidylethanolamine-binding proteins

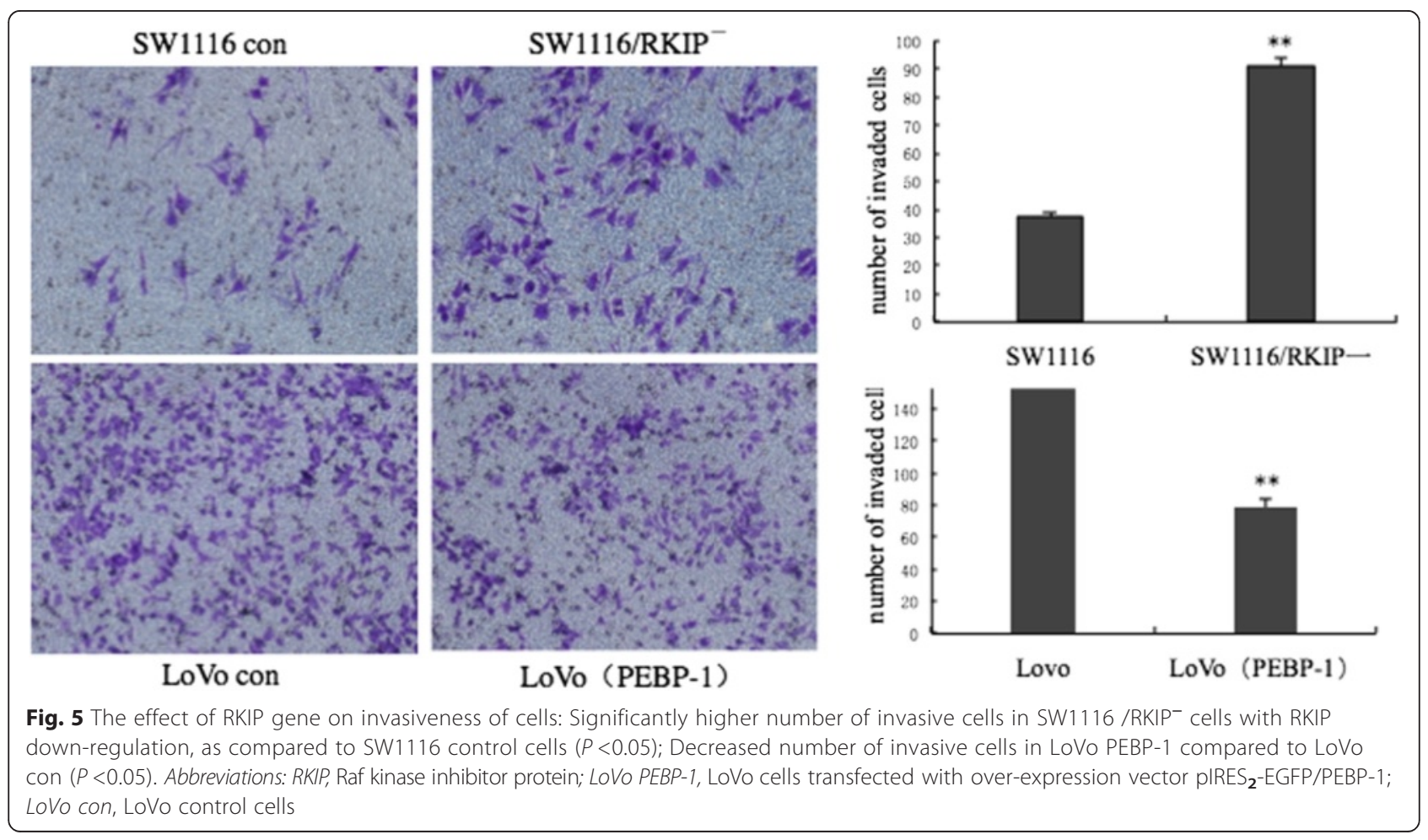


RKIP regulates cell cycle and the down-regulation of RKIP inhibits G1 cell cycle arrest and promotes cell proliferation: role of RKIP in cell cycle regulation

To avoid the impact of transfection reagent on cell cycle, we selected SW1116/RKIP- cells with steady downregulation of RKIP expression, instead of SW1116 cells transfected with RKIP shRNA. The percentage of cells at $\mathrm{S}$ and $\mathrm{G} 2 / \mathrm{M}$ phases by FCM was analysed by calculating the PI. PI $\%=(\mathrm{S}+\mathrm{G} 2 / \mathrm{M}) /(\mathrm{G} 0 / \mathrm{G} 1+\mathrm{S}+\mathrm{G} 2 / \mathrm{M}) \times 100$ was calculated. Down-regulation of RKIP decreased the cells in $\mathrm{G0} / \mathrm{G} 1$ phase $(48.6 \pm 2.12$ vs. $57.6 \pm 3.35, P<0.05)$ and increased the cells in $\mathrm{G} 2 / \mathrm{M}$ phase $(23.3 \pm 4.31$ vs. $14.9 \pm$ $2.35, P<0.05)$, thereby increasing the PI $(51.4 \pm 2.12 \mathrm{vs}$. $42.4 \pm 3.35, P<0.05$ ) (Fig. 6). This suggests an important effect of RKIP on the invasion and migration of SW1116 and LoVo cells, and that down-regulation of RKIP inhibits G1 cell cycle arrest and promotes cell proliferation. At the same time, LoVo cells transfected with
pIRES $_{2}$-EGFP/PEBP-1 and LoVo cells transfected with pIRES2-EGFP negative control plasmid were analyzed through flow cytometry to observe the effect of overexpression of RKIP gene on the ability of cell cycle. There were no significant difference between the two groups.

\section{Down-regulation of RKIP inhibited chemosensitivity of CRC cells to Hydroxycamptothecine}

The effects of RKIP expression on the chemosensitiviy of CRC to HCPT were observed by MTT (Fig. 7). The results represent mean $\pm \mathrm{SD}$ of three experiments. Hydroxycamptothecin-resistant cell line (SW1116/HCPT), derived from human colon cancer cell line SW1116 by treatment with step-wise increasing concentrations of HCPT has been described previously [22]. RKIP protein expression levels were verified again (Fig. 7a). Downregulation of RKIP increased IC50 values of HCPT in

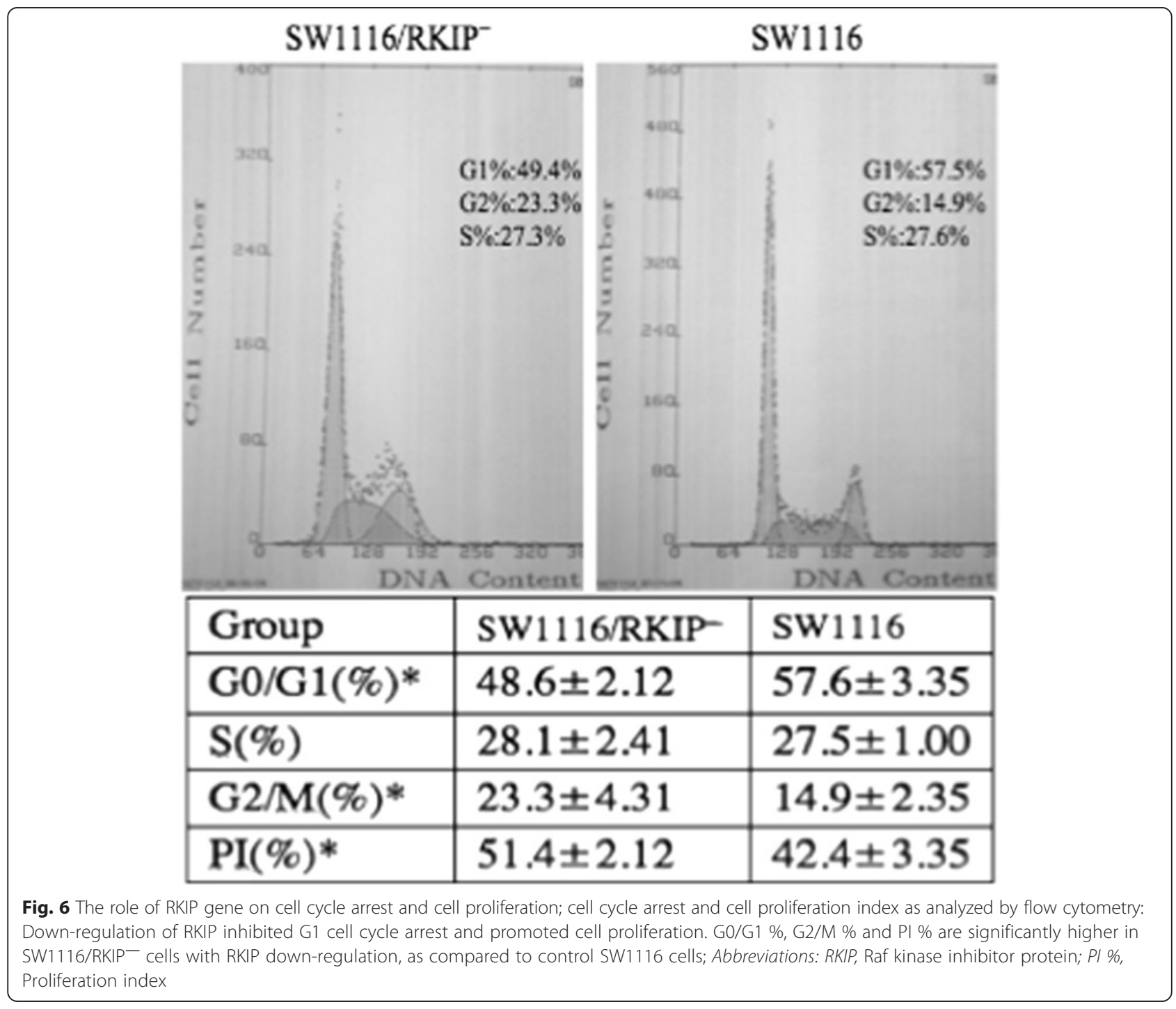




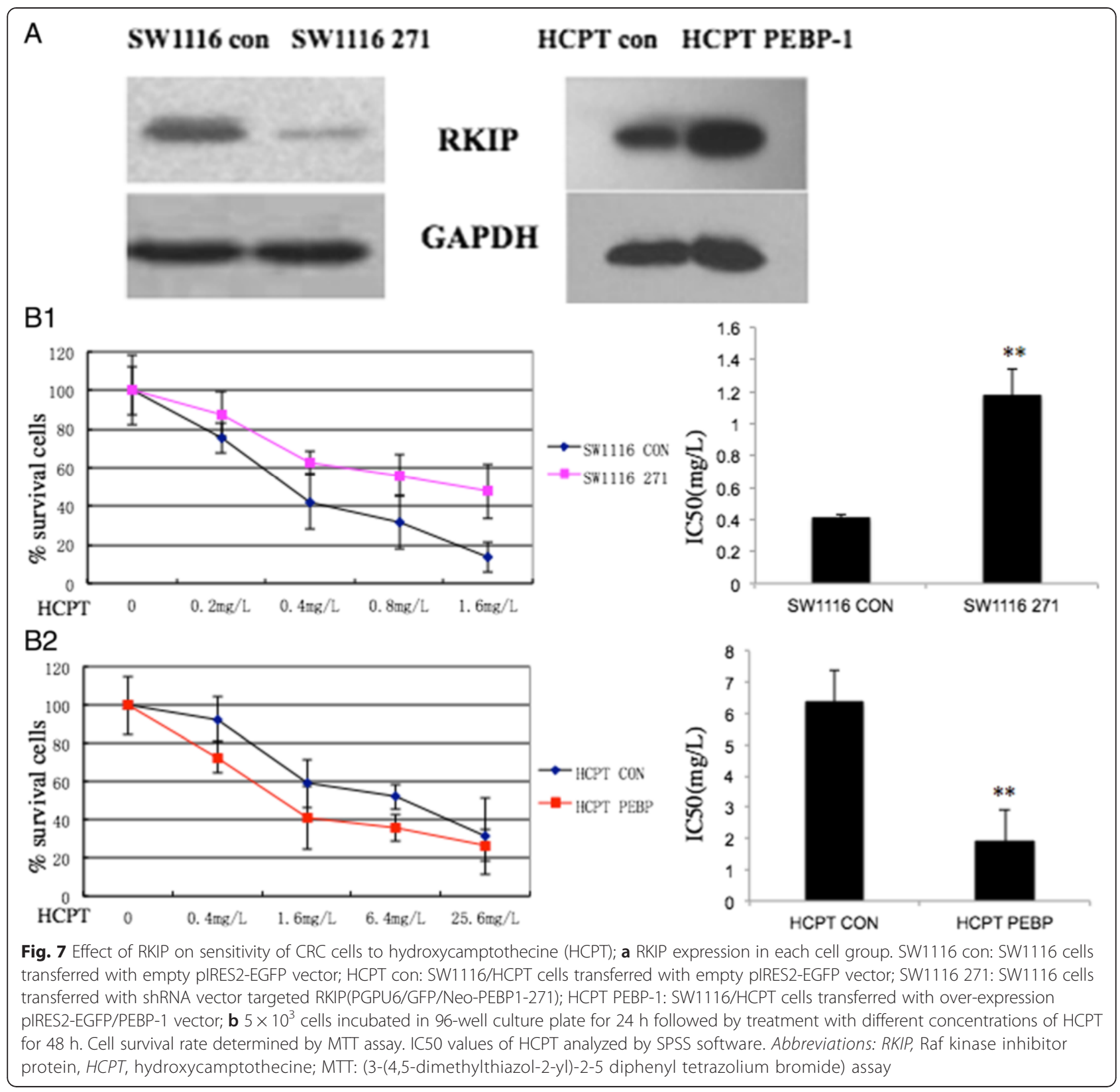

SW1116 cells: $1.176 \mathrm{mg} / \mathrm{L}$ (SW1116 con) vs. $0.410 \mathrm{mg} / \mathrm{L}$ (SW1116 271) (Fig. 7b1); whereas up-regulation of RKIP decreased the IC50 values of HCPT in SW1116/HCPT cells: $1.891 \mathrm{mg} / \mathrm{L}$ (HCPT PEBP) vs. $6.374 \mathrm{mg} / \mathrm{L}$ (HCPT CON) (Fig. 7b2). The results show that RKIP increases chemosensitivity of CRC cells to HCPT.

Down-regulation of RKIP inhibits HCPT-induced apoptosis After treatment with HCPT, SW1116 cells transfected with shRNA 271 vector and control vector for $48 \mathrm{~h}$ were analysed for evidence of apoptosis. As previously demonstrated, shRNA 271 vector down-regulate the expression of RKIP. The apoptosis rate was lower in SW1116 cells transfected with shRNA 271 vector than that in control cells $(0.08 \mathrm{mg} / \mathrm{mL}: 6.91 \% \pm 1.03 \%$ vs. $3.35 \% \pm$ $1.12 \% ; 0.16 \mathrm{mg} / \mathrm{mL} ; 22.54 \% \pm 2.24$ vs. $13.80 \% \pm 1.61$, $P=0.019$ and $P=0.005$, respectively; Fig. 8 ). It can be inferred from these experiments that that the downregulation of RKIP inhibits the chemosensitivity of CRC cells to HCPT by inhibiting apoptosis.

\section{Discussion}

Ras kinase inhibitor protein (RKIP) has been shown to be associated with metastatic disease in an increasing number of solid tumors. Dysregulation of RKIP expression can potentially be associated with many malignancies. RKIP 

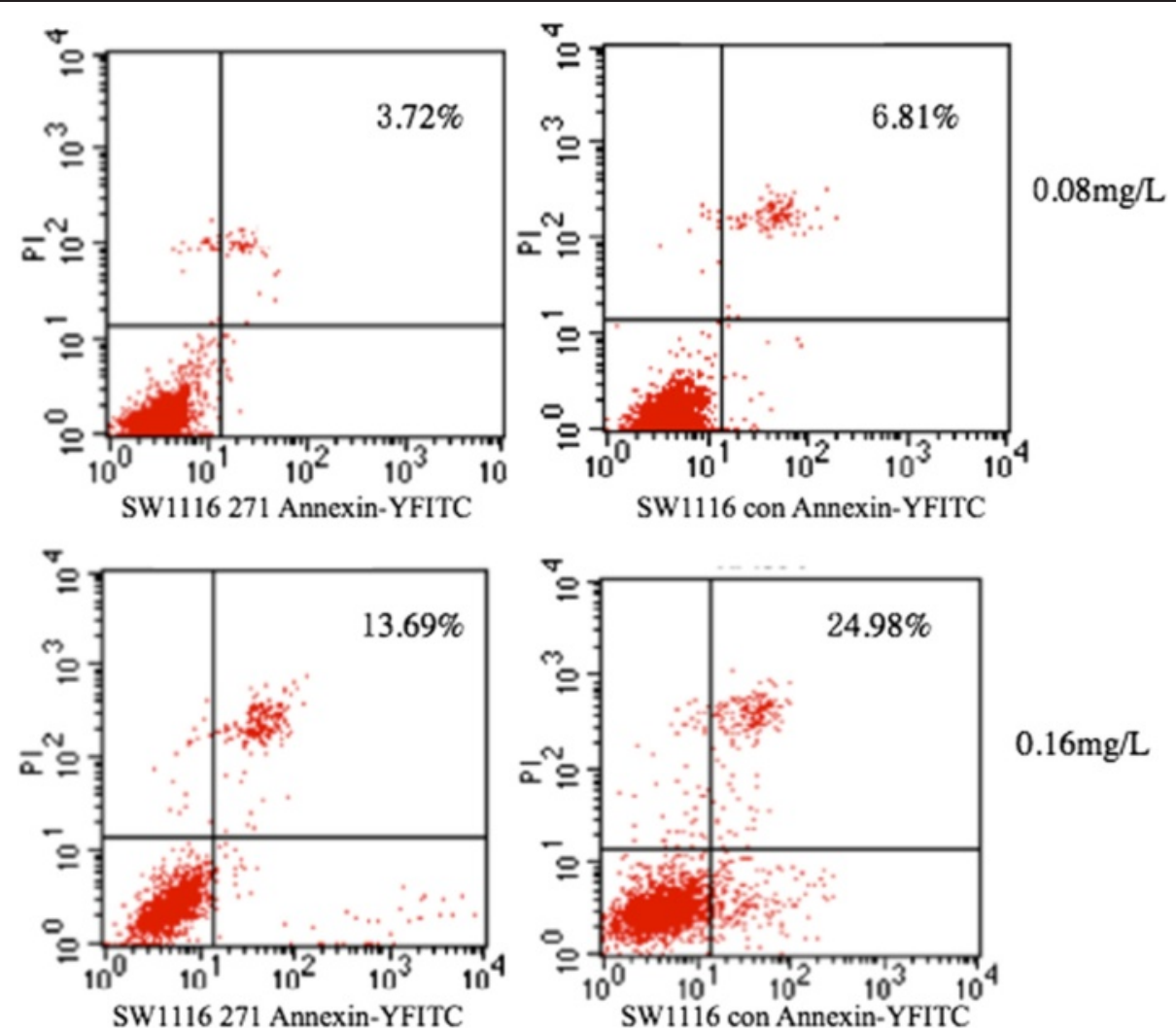

\section{$0.16 \mathrm{mg} / \mathrm{L}$}

Fig. 8 Apoptosis induction by hydroxycamptothecine (HCPT) in two group cells. Each group was treated with HCPT for $48 \mathrm{~h}$ at $0.08 \mathrm{mg} / \mathrm{L}$, $0.16 \mathrm{mg} / \mathrm{L}$ concentrations. $1 \times 10^{6}$ cells were collected and analyzed by flow cytometry after staining with Annexin V/PI

is initially expressed at a lower level in human metastatic prostate cancer cells as compared to that in nonmetastatic cancer cells, and may have a role in preventing vascular invasion of these cells [23]. RKIP expression is significantly decreased in insulinomas [24], anaplastic thyroid tumors [25], cutaneous squamous cell carcinoma [26], endometrial cancer [27], and hepatocellular carcinoma [28]. Studies have also shown reduced RKIP expression in lymph node metastases of breast and melanoma cancer [29, 8].

Several studies have demonstrated an association of RKIP with clinicopathological features in colorectal cancer. RKIP is depleted in distant metastases of both mismatch repair proficient and deficient colorectal cancers [18], and is a prognostic marker for disease-free survival [20] and distant metastatic disease [30]. Loss of RKIP in tumour buds has been frequently reported, with $60.8 \%$ of cases sustaining a complete loss in this area of CRC. Moreover, the loss of RKIP can help predict the dynamics of epithelial-mesenchymal transition (EMT) [31]. In our study the RKIP expression was decreased in CRCT when compared with NCRCT; but probably not to such an extent.

To the best of our knowledge, no in vivo and in vitro studies focusing on RKIP function in colorectal cancer cells have been conducted. Immunostaining results obtained in our study highlighted that RKIP is depleted in lymph node metastases and the activation of ERK is significant in CRC, both in-situ as well as in the CRC cell lines and metastatic lymph node tissue. There was a negative correlation between expression of RKIP and P-ERK. Moreover, our study demonstrated that RKIP expression was associated with the degree of differentiation of colorectal cancer cells, with higher expression occurring in well-differentiated cell lines (HT-29, SW1116) than in poorly differentiated cell lines (LoVo). Similarly, other studies have also demonstrated that Raf/MEK/ERK signaling pathway is associated with not only metastatic disease, but also differentiation in certain cell lines [32]. RKIP can induce differentiation and repression of cell proliferation in keratinocytes [33]. RKIP contributes to the monocytic differentiation process via inhibition of the NFkB signaling cascade, which is independent from the canonical Ras/Raf/MEK/ERK pathway [34]. Furthermore, RKIP has been shown to enhance neuronal differentiation via enhanced crosstalk from PKC to ERK-1/2, and enhancement of G-protein-coupled receptor signaling [35]. Some studies have suggested that RKIP may be dissociated from Raf- 1 after phosphorylation at serine 153 by PKC. In effect, PKC appears to relieve a key 
inhibitor of the Raf/MAP kinase signaling cascade [36]. As time constraints did not allow for a differential gene expression analysis, the details of underlying signaling pathway could not be determined.

Poorly differentiated LoVo cells transiently transfected with pIRES2-EGFP/PEBP-1 plasmid to cause overexpression of RKIP, were tested in matrixgel invasion and cell cycle assay. Over-expression of RKIP was found to inhibit invasion, but did not affect cell cycle and PI of LoVo cells. However, loss of RKIP function was found to inhibit G1 cell cycle arrest and increase cell PI (PI \%) in SW1116 cells (Fig. 6, PI: $51.4 \pm 2.12$ vs. $42.4 \pm 3.35$ ) in our study, the difference of PI is less than one fold; While the down-regulation of RKIP in SW1116/RKIPincreased the number of migrated cells on the lower surface of the matrigel-coated transwell membrane (Fig. 5, $90.67 \pm 4.04$ vs. $37.33 \pm 2.51, P<0.01$ ), the difference is two to three folds. The cell proliferation could complicate the interpretation of the results probably, but we thought that the role of cell invasion was more significant than the cell proliferation in results concluded from Fig. 5 in our study.

SW1116/RKIP ${ }^{-}$cells with stable down-regulation of RKIP expression were developed in our study, which perhaps minimized experimental error and cytotoxicity, as seen with the use of commercial liposome-based agents. Lipofectamine 2000, a cationic liposome based reagent, can change expression of marker genes for cell cycle inhibition or progression, such as p21 and PCNA, and also shows decrease in viability and DNA content [37]. We found that stable transfection as compared to transient transfection was more advantageous in terms of cell cycle assay.

A natural indole alkaloid extracted from a Chinese tree Camptotheca cuminata, HCPT is a topoisomerase Ispecific inhibitor [38]. Available evidence shows that HCPT can induce apoptosis in multiple cancers [39], and can also inhibit metastatic colorectal cancer [40]. HCPT treatment activates caspase 3 , and down regulates the expression of surviving [41]. Multidrug resistance gene ABCG2 and cell cycle related gene p21 had high expression in SW1116/HCPT cells [42, 22]. In our study, RKIP promoted cell apoptosis induced by HCPT, while the down-regulation of RKIP expression inhibited cell cycle arrest. Cell cycle capture allows cells to stop proliferating and repair the damage in order to continue cell division. Expression of p21 can protect cells from apoptosis induced by anticancer drugs. P21 is probably involved in RKIP regulated apoptosis induced by HCPT. RKIP overexpression appears to regulate tumor cell sensitivity to TRAIL by inhibiting YY1 and up-regulating DR5. RKIP overexpression in combination with TRAIL has been shown to potentiate the above effects and activate caspases 8,9 , and 3 , resulting in apoptosis [43].

\section{Conclusions}

In summary, RKIP is not only a metastasis inhibitor factor, but also related with colorectal cancer cell differentiation. Loss of RKIP inhibits cell cycle arrest and promotes cell proliferation. Furthermore, down-regulation of RKIP reduced chemosensitivity by inhibiting apoptosis induced by $\mathrm{HCPT}$. Our findings suggest that further investigation into the pathophysiological mechanisms of RKIP may help develop new therapeutic strategies for the treatment of colorectal cancer. Moreover, RKIP may serve as an immune surveillance cancer gene since its low expression (or absence) may serve as a marker for a likely poor immune response, that could serve to shield the tumor cells against the host cytotoxic effector cells.

\section{Competing interests}

The authors have declared that no competing interests exist.

\section{Authors' contributions}

Conceived and designed the experiments: FN.JGC.ZHR. Performed the experiments: FN JLT MMZ. Analyzed the data: FN MMZ. Contributed reagents/materials/analysis tools: FN.YG. Wrote the paper: FN ZHR. All authors read and approved the final manuscript.

\section{Acknowledgments}

This work was supported by the outstanding academic leader's project,Science and Technology Commission of Shanghai (No.10XD1402600) and the National Natural Science Foundation of China (NO:30770964).

\section{Author details}

Department of Intensive Care Medicine, Ren Ji Hospital, School of Medicine, Shanghai Jiao Tong University, Shanghai, China. ${ }^{2}$ Division of Gastroenterology and Hepatology, Ren Ji Hospital, School of Medicine, Shanghai Jiao Tong University, Shanghai Institute of Digestive Disease, 145 Middle Shandong Road, Shanghai 200001, China.

Received: 13 November 2014 Accepted: 2 July 2015

Published online: 16 July 2015

\section{References}

1. Park S, Young ML, Beach S, Shields JM, Yeung KC. RKIP down regulates BRaf kinase activity in melanoma cancer cells. Oncogene. 2005;24:3535-40.

2. Fu Z, Kitagawa Y, Shen R, Shah R, Mehra R, Rhodes D, et al. Metastasis suppressor gene Raf kinase inhibitor protein (RKIP) is a novel prognostic marker in prostate cancer. Prostate. 2006;66:248-56.

3. Li HZ, Gao Y, Zhao XL, Liu YX, Sun BC, Yang J, et al. Effects of raf kinase inhibitor protein expression on metastasis and progression of human breast cancer. Mol Cancer Res. 2009;7:832-40.

4. Jia B, Liu H, Kong Q, Li B. RKIP expression associated with gastric cancer cell invasion and metastasis. Tumour Biol. 2012;33:919-25.

5. Maresch J, Birner P, Zakharinov M,Toumangelova-Uzeir K, Natchev S, Guentchev M. Additive effect on survival of Raf kinase inhibitor protein and signal transducer and activator of transcription 3 in high-grade glioma. Cancer. 2011;117:2499-504

6. Huerta-Yepez S, Yoon NK, Hernandez-Cueto A, Mah V, Rivera-Pazos CM, Chatterjee D, et al. Expression ofphosphorylated raf kinase inhibitor protein ( $p R K I P$ ) is a predictor of lung cancer survival. BMC Cancer. 2011;11:259.

7. Li B, Sun B, Zhu J, Zhou N, Yang Z, Gu J.. Expression of RKIP in chronic myelogenous leukemia K562 cell and inhibits cell proliferation by regulating the ERK/MAPK pathway. Tumour Biol. 2014;35:10057-66.

8. Schuierer MM, Bataille F, Hagan S, Kolch W, Bosserhoff AK. Reduction in Raf kinase inhibitor protein expression is associated with increased Rasextracellular signal-regulated kinase signaling in melanoma cell lines. Cancer Res. 2004;64:5186-92. 
9. Yeung KC, Rose DW, Dhillon AS, Yaros D, Gustafsson M, Chatterjee D, et al. Raf kinase inhibitorprotein interacts with NF-kappaB-inducing kinase and TAK1 and inhibits NF-kappaB activation. Mol Cell Biol. 2001;21:7207-17.

10. Huang J, Mahavadi S, Sriwai W, Grider JR, Murthy KS. Cross-regulation of VPAC(2) receptor desensitization by M(3) receptors via PKC-mediated phosphorylation of RKIP and inhibition of GRK2. Am J Physiol Gastrointest Liver Physiol. 2007;292:G867-74.

11. Lorenz K, Lohse MJ, Quitterer U. Protein kinase C switches the Raf kinase inhibitor from Raf-1 to GRK-2. Nature. 2003:426:574-9.

12. Ruan L, Wang GL, Yi H, Chen Y, Tang CE, Zhang PF,et al. Raf kinase inhibitor protein correlates with sensitivity of nasopharyngeal carcinoma to radiotherapy. J Cell Biochem. 2010;110:975-81.

13. Chatterjee D, Bai Y, Wang Z, Beach S, Mott S, Roy R, et al. RKIP sensitizes prostate and breast cancer cells to drug-induced apoptosis. J Biol Chem. 2004:279:17515-23.

14. Ma J, Li F, Liu L, Cui D, Wu X, Jiang $X$, et al. Raf kinase inhibitor protein inhibits cell proliferation but promotes cell migration in rat hepatic stellate cells. Liver Int. 2009;29:567-74.

15. Houben R, Ortmann S, Becker JC, RKIP does not contribute to MAP kinase pathway silencing in the Merkel Cell Carcinoma cell line UISO. J Carcinog. 2007;24:16

16. Parkin DM, Bray F, Ferlay J, Pisani P. Global cancer statistics. Cancer J Clin. 2007:55:74-108

17. Al-Mulla F, Bitar MS, Feng J, Park S, Yeung KC. A new model for raf kinase inhibitory protein induced chemotherapeutic resistance. PLoS One. 2012;7, e29532.

18. Minoo P, Zlobec I, Baker K, Tornillo L, Terracciano L, Jass JR, et al. Loss of Raf-1 kinase inhibitor protein expression is associated with tumor progression and metastasis in colorectal cancer. Am J Clin Pathol. 2007;127:820-7.

19. Lin BR, Huang MT, Chen ST, Jeng YM, Li YJ, Liang JT, et al. Prognostic significance of TWEAK expression in colorectal cancer and effect of its inhibition on invasion. Ann Surg Oncol. 2012;19:385-94.

20. Al-Mulla F, Hagan S, Abdulla I, Bitar MS, George SS, Going JJ, et al. Raf kinase inhibitor protein expression in a survival analysis of colorectal cancer patients. J Clin Oncol. 2006:24:5672-9.

21. Zou J, Ran ZH, Huang ML, Xiao Shudong. Construction and characterization of hydroxycamptothecin-resistant human colon cancer cell line SW1116/ HCPT. Chin J Gastroenterol. 2006;11:327-31.

22. Ming Ming Z, Jin Lu T, Qi X, Nie F, Xu XT, Xiao SD, et al. Increased JNK1 signaling pathway is responsible for ABCG2-mediated multidrug resistance in human colon cancer. Plos one. 2012;7:e41763. doi:10.1371/ journal.pone.0041763.

23. Fu Z, Smith PC, Zhang L, Rubin MA, Dunn RL, Yao Z,et al. Effects of raf kinase inhibitor protein expression on suppression of prostate cancer metastasis. J Natl Cancer Inst. 2003;95:878-89.

24. Zhang L, Fu Z, Binkley C, Giordano T, Burant CF, Logsdon CD, et al. Raf kinase inhibitory protein inhibits beta-cell proliferation. Surgery. 2004;136:708-15.

25. Akaishi J, Onda M, Asaka S, Okamoto J, Miyamoto S, Nagahama M,et al. Growth-suppressive function of phosphatidyl ethanolamine-binding protein in anaplastic thyroid cancer. Anticancer Res. 2006;26:4437-42.

26. Zaravinos A, Kanellou P, Baritaki S, Bonavida B, Spandidos DA. BRAF and RKIP are significantly decreased in cutaneous squamous cell carcinoma. Cell Cycle. 2009;8:1402-8

27. Martinho O, Faloppa CC, Scapulatempo Neto C, Longatto-Filho A, Baiocchi G, da Cunha IW, et al. Loss of RKIP expression during the carcinogenic evolution of endometrial cancer. J Clin Pathol. 2012;65:122-8.

28. Lee HC, Tian B, Sedivy JM, Wands JR, Kim M. Loss of Raf kinase inhibitor protein promotes cell proliferation and migration of human hepatoma cells. Gastroenterology. 2006;131:1208-17

29. Hagan S, Al-Mulla F, Mallon E, Oien K, Ferrier R, Gusterson B,et al. Reduction of Raf-1 kinase inhibitor protein expression correlates with breast cancer metastasis. Clin Cancer Res. 2005;11:7392-7.

30. Zlobec I, Baker K, Minoo P, Jass JR, Terracciano L, Lugli A. Node-negative colorectal cancer at high risk of distant metastasis identified by combined analysis of lymph node status, vascular invasion, and Raf-1 kinase inhibitor protein expression. Clin Cancer Res. 2008;14:143-8.

31. Koelzer VH, Karamitopoulou E, Dawson H, Kondi-Pafiti A, Zlobec I, Lugli A. Geographic analysis of RKIP expression and its clinical relevance in colorectal cancer. Br J Cancer. 2013;108:2088-96.
32. Gredinger E, Gerber AN, Tamir Y, Tapscott SJ, Bengal E. Mitogen-activated protein kinase pathway is involved in the differentiation of muscle cells. J Biol Chem. 1998;273:10436-44.

33. Yamazaki T, Nakano H, Hayakari M, Tanaka M, Mayama J, Tsuchida S. Differentiation induction of human keratinocytes by phosphatideylethanolamine-binding protein. J Biol Chem. 2004;279:32191-5.

34. Schuierer MM, Heilmeier U, Boettcher A, Ugocsai P, Bosserhoff AK, Schmitz $\mathrm{G}$, et al. Induction of Raf kinase inhibitor protein contributes to macrophage differentiation. Biochem Biophys Res Commun. 2006;342:1083-7.

35. Ms Q, Green S. PC12 cell neuronal differentiation is associated with prolonged p21 ras activity and consequent prolonged ERK activity. Neuron. 1992;9:705-17.

36. Corbit KC, Trakul N, Eves EM, Diaz B, Marshall M, Rosner MR.. Activation of Raf-1 signaling by protein kinase $C$ through a mechanism involving Raf kinase inhibitory protein. J Biol Chem. 2003;278(15):13061-8.

37. Yang HY, Vonk LA1, Licht R,van Boxtel AM1, Bekkers JE, Kragten AH, et al. Cell type and transfection reagent-dependent effects on viability, cell content, cell cycle and inflammation of RNAi in human primary mesenchymal cells. Eur J Pharm Sci. 2014;53:35-44.

38. Alagoz M, Gilbert DC, El-Khamisy S, Chalmers AJ. DNA repair and resistance to topoisomerase I inhibitors: mechanisms, biomarkers and therapeutic targets. Curr Med Chem. 2012;19:3874-85.

39. Zhang G, Ding L, Renegar R, Wang X, Lu Q, Huo S, et al. Hydroxycamptothecin-loaded Fe3O4 nano-particles induce human lung cancer cell apoptosis through caspase-8 pathway activation and disrupt tight junctions. Cancer Sci. 2011;102:1216-22.

40. Hu W, Zhang C, Fang Y, Lou C. Anticancer properties of 10hydroxycamptothecin in a murine melanoma pulmonary metastasis model in vitro and in vivo. Toxicol In Vitro. 2011;25:513-20.

41. Fei B, Chi AL, Weng Y. Hydroxycamptothecin induces apoptosis and inhibits tumor growth in colon cancer by the down-regulation of survivin and XIAP expression. World J Surg Oncol. 2013;11:120-9.

42. Huang ML, Ran ZH, Zou J, Xiao SD. Expression of drug resistance-related genes in hydroxycamptothecin-resistant human colon cancer SW1116/HCPT cells. Chin Tumor. 2007;27:96-100.

43. Baritaki S, Katsman A, Chatterjee D, Yeung KC, Spandidos DA, Bonavida B. Regulation of tumor cell sensitivity to TRAlL-induced apoptosis by the metastatic suppressor Raf kinase inhibitor protein via Yin Yang 1 inhibition and death receptor 5 up-regulation.

J Immunol. 2007;179:5441-53.

\section{Submit your next manuscript to BioMed Central and take full advantage of:}

- Convenient online submission

- Thorough peer review

- No space constraints or color figure charges

- Immediate publication on acceptance

- Inclusion in PubMed, CAS, Scopus and Google Scholar

- Research which is freely available for redistribution 